\title{
Total kalça artroplastisinde venöz tromboemboli profilaksisi
}

\author{
Venous thromboprophylaxis in total hip arthroplasty
}

\author{
Korhan Özkan ${ }^{1}$, Esat Uygur², Feyza Ünlü Özkan³ \\ ${ }^{1}$ Medeniyet Üniversitesi Tıp Fakültesi, Ortopedi ve Travmatoloji Anabilim Dalı \\ ${ }^{2}$ S.B. Medeniyet Üniversitesi Göztepe Eğitim ve Araştırma Hastanesi, Ortopedi ve Travmatoloji Anabilim Dalı \\ ${ }^{3}$ S.B. Fatih Sultan Mehmet Eğitim ve Araştırma Hastanesi, Fizik Tedavi ve Rehabilitasyon Kliniği
}

\begin{abstract}
Majör cerrahi müdahaleler dikkate alındığında, venöz tromboemboli (VTE) riskini en fazla arttıran iki ameliyat total kalça ve total diz artroplastisidir. VTE konusu, ortaya çıkabilecek pulmoner emboli gibi ölümcül komplikasyonlar nedeniyle artroplasti cerrahisinde oldukça önemli bir yer tutmaktadır. Herhangi bir profilaksi yöntemi kullanılmaması durumunda VTE gelişim riski total kalça artroplastisinde \%60'lara kadar çıkabilmektedir. VTE'nin hastanede gerçekleşen her on ölümün birinden sorumlu olduğu göz önüne alınırsa, VTE gelişimini önlemek daha etkin, akıllıca ve maliyet açısından daha uygun bir yöntem olarak karşımıza çıkmaktadır. Günümüzde VTE profilaksisine yönelik birçok farklı yöntem tercih edilmekte ise de bu konuda kesin kanıtlanmış veriler sınırlıdır; kullanılacak yöntemler ve süresine ilişkin tartışmalar halen devam etmektedir. Son yıllarda gündeme gelen oral kullanıma uygun antikoagülan ilaçların tercihi giderek artmakta ve sonuçları umut vadetmektedir. Farmakolojik araştırmalar devam ederken, keşfedilen yeni ilaçlar uygulama kolaylığı getirmekle birlikte sorunları tam anlamıla çözmüş değildir. Bu derlemede güncel literatür bilgilerini inceleyerek total kalça artroplastisi sonrası VTE profilaksisine ışık tutmayı amaçladık.
\end{abstract}

Anahtar sözcükler: artroplasti; total kalça replasmanı; venöz tromboembolizm; tromboz
Total hip and total knee arthroplasties constitute the highest risk of venous thromboembolism (VTE) comparing to other major surgeries. VTE has a great importance in joint replacement surgery due to its mortal complications such as pulmoner embolism. Without any thromboprophylaxis, the incidence of VTE in total hip arthroplasty rises up to $60 \%$. Taking into consideration that VTE is responsible for $1 / 10$ patients' death in hospitalized patients; prevention of VTE seems to be more eligible, more logical and more cost-effective. Nowadays, although there are so many different techniques in preventing VTE, well proved data is still limited and continuing debates about prevention technique and timing are still going on. In recent years, administration of oral anticoagulants has been associated with increased preference and promising results. Pharmacologic investigations are still going on with new drugs providing utilization comfort, but problems are not completely overcome. In this review, we aimed to discuss VTE prophylaxis after total hip arthroplasty under current literature knowledge.

Key words: arthroplasty; total hip replacement; venous thromboembolism; thrombosis

hastaların yaklaşık \%12'si beş yıl içinde ikinci bir VTE ile karşılaşmaktadır. ${ }^{[1,2]}$ Pulmoner emboli (PE)'nin ölümcül olabileceği ve tedavi seçeneklerinin kısıtlı olduğu göz önüne alınırsa, PE gelişimini önlemek daha uygun, akıllıca ve daha düşük maliyetli bir yaklaşımdır. Büyük cerrahi müdahaleler dikkate alındığında VTE riskini en fazla arttıran iki ameliyat total kalça ve total diz artroplastisidir. ${ }^{[3]}$ Buna rağmen VTE, ortopedik cerrahi pratiğinde halen tartışmalı konular arasında

- İletişim adresi: Dr. Korhan Özkan, S.B. Medeniyet Üniversitesi, Göztepe Eğitim ve Araştırma Hastanesi Ortopedi ve Travmatoloji Anabilim Dalı, İstanbul Tel: 0216 - 5709105 e-posta: korhanozkan76@gmail.com

- Geliș tarihi: 28 Mart 2013 Kabul tarihi: 25 Haziran 2013 
yer almaktadır. ${ }^{[4]}$ VTE konusundaki bitmeyen bu tartışmaların bir nedeni de yapılan çalışmaların çoğunun ilaç şirketleri tarafindan finanse edilmesidir. Yapılan bir araştırmada anlamlı çalışmaların \%79'unun ticari şirketler tarafından finanse edildiği gösterilmişse de bu ilaçların kullanılmasıyla VTE profilaksisi ve tedavisinde önemli yollar kat edilmiştir. ${ }^{[5]}$ Biz bu derleme makalede, son yıllardaki temel yayınları göz önüne alarak total kalça artroplastisinde VTE profilaksisinin ana hatlarını ortaya koymayı amaçladık.

\section{PROFILAKSI YÖNTEMLERI NE OLMALI?}

\section{1) Mekanik Profilaksi}

Mekanik profilaksi temelde kompresyon cihazları ile venöz stazın azaltılması ve fibrinolizisin arttırılmasına dayanır. Ancak en sık karşılaşılan sorun hasta uyumudur.

a) Varis Çorabı ve Pnömatik Kompresyon: Sadece majör kanama problemi olan hastalarda tek başına kullanılabilir ancak hasta uyumu ciddi bir sorun teşkil etmektedir. ${ }^{[6]}$

b) Vena Cava Filtresi: Sadece daha önce derin ven trombozu veya PE öyküsü olan ve antikoagülan ajan kullanımının uygun olmadığı majör travma geçirmiş hastalarda kullanılmalıdır. Pahalı ve invaziv bir yöntemdir. Ancak kemoprofilaksinin uygun olmadığı kalça artroplastisi yapılacak hastalarda vena cava filtresinin kullanımıyla ilgili olumlu ya da olumsuz net bir kanıt ortaya koyulamamıştır. ${ }^{[7]}$

\section{2) Medikal Profilaksi (Kemoprofilaksi)}

VTE profilaksisinde kullanılacak ilaçlar dikkate alındığında ideal bir ilacın hızı etkili, güvenli, uygulaması kolay, diğer ilaç veya besinlerle etkileşime girmeyen, ucuz, doz ayarı kolay yapılan, laboratuvar izlemi gerektirmeyen ve olası bir kanama probleminde antidotu olan bir preparat olması istenir.

\section{Warfarin}

$\mathrm{K}$ vitamini antagonisti olarak etki eden oral preparattır. Oral kullanımı avantajdır, ancak monitorizasyonu gerekir. Etkili bir profilaksi sağlaması için INR düzeyinin 2,5 (2,0-3,0) olması gerekmektedir. Ayrıca alınan gıda ya da diğer ilaçlarla etkileşime girebileceğinden doza dikkat edilmelidir. Bunun yanı sıra uzun yarılanma ömrü nedeniyle etkisinin günler sonra bile devam ediyor oluşu dezavantajlarındandır.

\section{Düşük molekül ağırlıklı heparin (DMAH)}

Hızlı etkili oluşu, yarılanma ömrünün 4,5 saat oluşu ve monitorizasyon gerektirmemesi avantajlarındandır.
Ancak bunların yanında diğer profilaktik ajanlara nazaran pahalıdır ve kanama riski yüksektir. Yapılan bir çalışmaya göre total kalça artroplastisinde warfarine kıyasla küçük kanamaları belirgin şekilde arttırdığı gösterilmiştir. ${ }^{[8]}$ ACCP (American Collage of Chest Physicians) kılavuzlarına göre total kalça, total diz artroplastileri ve kalça kırıklarında DMAH kullanımı önerilmektedir.

\section{Fondaparinux}

Faktor Xa inhibitörü yapay beşşekerli parenteral kullanılan bir ilaçtır. Bir çalışmada tromboembolik komplikasyonları belirgin düzeyde düşürmekle birlikte, istenmeyen kanamaları da ciddi şekilde arttırdığı gösterilmiştir. ${ }^{[9]}$

\section{Asetil Salisilik Asit (ASA)}

Aspirin; ucuz, oral kullanılabilen ve herhangi bir monitorizasyon gerektirmeyen bir profilaktik ajandır. Bir çalışmada ASA'ya ek olarak mekanik kompresyon ile DMAH karşılaştırılmış ve her iki grubun etkinliği arasında bir fark bulunamamıştır. ${ }^{[10]}$ Yapılan başka bir çalışmada ASA veya warfarin ile gerçekleştirilen profilakside heparin veya DMAH'a nazaran kanamaya dair daha az komplikasyon bildirilmiştir. ${ }^{[11]}$ Ancak ASA'nın mutlaka DMAH ile birlikte kullanılmasını öneren yayınlar da mevcuttur. ${ }^{[12]}$ Bu bakımdan, VTE profilaksisinde aspirinin tek başına kullanılması günümüzde oldukça tartışmalıdır. Aspirin, VTE profilaksisi için sadece yüksek kanama riski olanlarda mekanik profilaksi ile birlikte uygulanmalıdır.

\section{Dabigatran}

Direkt etkili, oral kullanılan trombin (Faktör II) inhibitörüdür. Yapılan geniş kapsamlı RE-MODAL ve RE-NOVATE çalışmalarında günlük $150-220 \mathrm{mg}$ tek doz olarak kullanılan dabigatranın enoxaparin kadar etkili ve kanama açısından da güvenli olduğu bulunmuştur. ${ }^{[13]}$

\section{Rivaroksaban}

Direkt etkili oral kullanılan Faktör Xa inhibitörüdür. Etkisi hızlı başladığından ek olarak yanında başka bir antikoagülan kullanımına gerek yoktur. 4541 kişide yapılan bir çalışmada Rivaroksabanın belirgin bir kanama sorununa yol açmadan VTE'yi önlemede cilt altı enoksaparin enjeksiyonuna göre daha etkin olduğu ortaya konmuştur. ${ }^{[14]}$

Literatürdeki derleme makaleler incelenerek oluşturulan kılavuzlar dikkate alınırsa, VTE konusunda çeşitli öneriler öne çıkmaktadır. Bu kılavuzlar bilimsel çalışma kanıt düzeyi ve öneri gücü derecesine göre yorumlanır (Tablo 1 ve 2). 
Tablo 1. Bilimsel Çalışma Kanıt Düzeyi
I Yüksek kaliteli randomize çalışma
II Kontrollü kohort çalışması
III Olgu-kontrollü çalışma
IV Kontrol grubu olmadan olgu serisi/serileri
V Uzman görüşleri

Tablo 2. Öneri Gücü Derecesi
A İyi kanıtlanmış: I. kanıt düzeyli (kaliteli ve uygulanabilir) çalışmalarla desteklenmiş veri.
B Yeterli Kanıtlanmış: II. ve III. kanıt düzeyli (kaliteli ve uygulanabilir) çalışmalarla desteklenmiş veri.
C Zayıf kanıtlanmış: IV. ve V. kanıt düzeyli çalışmalarla desteklenmiş veri.
D Yetersiz veya tartışmalı veri. Öneri olarak kabul edilmemeli.

Haas SB, et al.[19]

AAOS'un (American Academy of Orthopaedic Surgeons) 2011 yılına ait, total kalça ve total diz artroplastileri sonrasında VTE'yi önleme konusundaki derlemesinde öneriler şöyle sıralanmaktadır:

Öneri 1.1: Ameliyat öncesi her hasta normale göre artmış VTE riski açısından değerlendirilmelidir (Düzey III, derece B).

Öneri 1.2: Ameliyat öncesi her hasta normale göre artmış majör kanama riski açısından değerlendirilmelidir (Düzey III, derece C). 2012 yılına ait rehberde ise özellikle hastanın karaciğer yetmezliği ve hemofili gibi kanama problemi yaratacak ek hastalığının araştırılması konusunda fikir birliği sağlanmıştır. ${ }^{[7]}$

Öneri 1.3: Antikoagulan ilaçların uygun olmadığı bilinen bir hasta için vena cava filtresi kullanımı düşünülmelidir (Düzey $\mathrm{V}$, derece $\mathrm{C}$ ).

Öneri 2.1: Hastalara ameliyat öncesi veya ameliyattan hemen sonra mekanik profilaksi planlanmalıdır (Düzey III, derece B).

Öneri 2.2: Hastanın anestezi doktoru tarafından değerlendirilmesi de sağlanarak, mümkünse bölgesel anestezi uygulanmalıdır (Düzey IV, derece C).

Öneri 3.1: Ameliyat sonrası hastalar hastaneden taburcu olana dek mekanik profilaksiye devam edilmelidir (Düzey IV, derece C).
Öneri 3.2: Ameliyat sonrası hastalar mümkün olan en kısa zamanda hareketlendirilmelidir. (Düzey V, derece $C$ ).

Öneri 3.4: Ameliyat sonrası derin ven trombozu (DVT) ya da PE açısından rutin takip önerilmemektedir (Düzey III, derece B).

Öneri 4.1: Hastalar hastaneden taburcu edildikten sonra evde de hareketlenme konusunda cesaretlendirilmelidir. (Düzey $\mathrm{V}$, derece $\mathrm{C}$ ).

Öneri 4.2: Hastalar DVT ve PE'nin belli başlı belirti ve bulguları konusunda eğitilmelidir. (Düzey $\mathrm{V}$, derece $C$ ).

Öneri 3.3: Total kalça ve total diz artroplastisi cerrahisinde kemoprofilaksiye ilişkin öneriler:

Öneri 3.3.1: PE ve ciddi kanama açısından normal risk teşkil eden hastalar için asetil salisilit asit (ASA), düşük molekül ağırlıklı heparin (DMAH), yapay beşşekerliler (pentasakkaritlerFondaparinux) veya warfarinden biri kullanılmalıdır (Düzey III, derece B (profilaktik ilacın tipine göre - derece $C$ dozlama ve zamanlamaya göre).

Öneri 3.3.2: PE ve ciddi kanama açısından normale göre artmış risk teşkil eden hastalar için DMAH, yapay beşşekerliler (pentasakkaritlerFondaparinux) veya warfarinden biri kullanılmalıdır (Düzey III, derece B profilaktik ilacın tipine göre - derece $C$ dozlama ve zamanlamaya göre).

Öneri 3.3.3: PE açısından normal risk faktörleri bulunan; ciddi kanama için ise, normale göre artmış riski bulunan hastalarda ASA veya warfarin kullanılmalıdır (Düzey III, derece C).

Öneri 3.3.4: PE ve ciddi kanama için normale göre artmış riski bulunan hastalarda ASA veya warfarin kullanılmalıdır (Düzey III, derece C).

AAOS'un (American Academy of Orthopaedic Surgeons) 2012 yılına ait, total kalça ve total diz artroplastileri sonrasında VTE'yi önleme konusundaki derlemesinde, 2011 yılındaki rehberden bazı farklılıklar dikkati çekmektedir:

Total kalça ve diz artroplastisi öncesinde antiplatelet ajanların (ASA ve Klopidogrel) kesilmesi, orta düzey öneri olarak kabul görmüştür. ${ }^{[7]}$

Geçirilmiş VTE öyküsü olan hastaların farmakolojik ve mekanik profilaksi yöntemlerinin kullanımı konusunda fikir birliği sağlanmıştır. ${ }^{[7]}$

Kanama problemi olan hastalarda kompresif mekanik profilaksi cihazlarının kullanılması konusunda fikir birliği sağlanmıştır. ${ }^{[7]}$ 
Elektif total kalça ve total diz protezi ameliyatı için hastaların nöroaksial anestezi (epidural, spinal anestezi) almalarının VTE riskini de arttırmadığı; aynı zamanda ameliyat esnasındaki kanamanın azaltılması için tercih edilebileceği orta düzey öneri olarak kabul edilmiştir. ${ }^{[7]}$

Vena kava filtresi kullanımı konusunda ise kemoprofilaksinin uygun olmadığı vakalarda dahi fikir birliği sağlanmamış olup tartışmalı olarak kabul edilmiştir. ${ }^{[7]}$

\section{PROFILAKSI NE ZAMAN BAŞLAMALI?}

DMAH'ların etkinliği 2 saat içinde başlar, 4. saatte dolaşımda en yüksek konsantrasyona ulaşır ve 12 saatte konsantrasyonu yarılanır. Dolayısıyla profilaktik olarak DMAH'a başlamak için geçerli yöntemlerden biri, ameliyattan 12 saat önce; diğeri de, ameliyattan 12-24 saat sonra şeklindedir. ${ }^{[12]}$

Warfarin ile profilakside ise ameliyat günü ameliyattan önce veya sonra başlanabilir. ${ }^{[12]}$

Fondaparinux ise genellikle cerrahiden 6-8 saat sonra başlanmalıdır. ${ }^{[9]}$

Rivaroksaban ve dabigatran profilaksisi yine ameliyattan $6-8$ saat sonra uygulanmalıdır. ${ }^{[13,14]}$

\section{PROFILAKSI NE KADAR SÜRMELI?}

Total kalça artroplastisi sonrası DMAH ile 42 günlük veya Fondaparinux ile 35 günlük uzatılmış tromboemboli profilaksisi önerilmektedir. ${ }^{[15]}$ Rivaroksaban ile yine 35 günlük uzatılmış tedavi önerilmektedir. ${ }^{[13]}$

\section{ÖZELLIKLI DURUMLARDA PROFILAKSI}

Warfarin kullanan hastalarda etkin ilaç dozu sağlanmışsa INR değeri 2,0'ın üzerindedir. Bu durum elektif cerrahi için uygun değildir ve planlanan ameliyat için yükselmiş olan INR değeri 1,5'in altına indirilmelidir. K vitamini antagonisti olarak işlev gösteren warfarinin etkisini ortadan kaldırmak amacıyla hastaya $\mathrm{K}$ vitamini takviyesi yapılmalıdır. Ancak K vitamininin etkisi nispeten geç (ortalama 8 saat sonra) ortaya çıktığından INR'deki düşüşü hızlandırmak için taze donmuş plazma ile kanda eksik olan pıhtılaşma faktörleri hastaya transfüze edilmelidir. Bu şekilde INR değeri güvenli aralığa çekildikten sonra cerrahi tedavi gerçekleştirilebilir. ${ }^{[12,16]}$

ASA ve klopidogrel ise, antitrombotik etkinliğe sahip, trombosit agregasyonunu önleyen ve oral olarak kullanılan ilaçlardır. Klopidogrel genelde kardiyak veya beynin iskemik hadiselerinde ortopedik cerrahi dışındaki hekimlerce tercih edilir. Her ikisi de laboratuvarda kanama zamanını uzatırlar. ASA veya

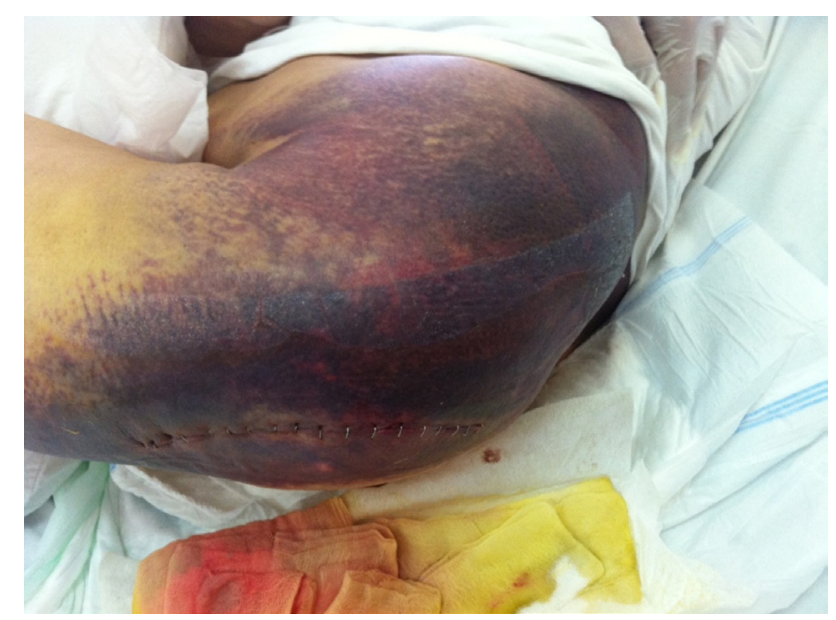

Şekil 1. VTE profilaksisi amacıyla ameliyat sonrasında Enoksaparin uygulanan bir total kalça artroplastisi olgusunda gelişen yaygın hematom.

klopidogrel kullanmakta olan bir hastaya elektif cerrahi planlanırsa, ameliyattan 7 gün önce ilacın kesilmiş olması gerekmektedir. ${ }^{[7]}$ ASA veya klopidogrelin etkisini ortadan kaldırmak için herhangi bir farmakolojik ajan bulunmamaktadır. Etkinliğini yok etmek, ancak trombosit süspansiyonu transfüzyonu ile kana yeni -agregasyon kabiliyeti bozulmamış- trombositlerin eklenmesiyle sağlanabilir. ${ }^{[12,16]}$

\section{SONUÇ}

Kalça artroplastisi cerrahisinde:

- Ameliyat sonrası hasta hareket kabiliyeti kazanana dek yapılan mekanik profilaksi (varis çorabı veya pnömatik kompresyon cihazı ile), VTE'yi önlemede kullanılacak en basit ve temel kuraldır.

- Ameliyat sonrası monitorizasyon gerektirmediğinden, istenmeyen bir etki olduğunda telafisi kolay olduğundan ve yatan hastaya kolay uygulanabildiğinden DMAH tedavisi tercih edilebilir. Ancak kanama eğilimi olan hastalarda dikkatli olunmalı; cerrahi öncesi spinal veya epidural anestezi teknikleri uygulanmışsa, cilt altı enjeksiyon ameliyattan 12 saat sonraya ertelenmelidir. Ayrıca yara yerinde ciddi bir kanama ve drenaj söz konusu olduğunda DMAH dozu düşürülebilir veya kesilerek mekanik profilaksiyle birlikte 200 $\mathrm{mg} /$ gün ASA tedavisine geçilebilir (Şekil 1). [17,18]

- Kanama riski olan hasta grubunda DMAH yerine ASA kullanılabilir, ancak ASA kullanırken mekanik profilaksi kesinlikle ihmal edilmemelidir. 
- Hasta taburcu edildikten sonra; VTE profilaksisi ameliyat sonrası 35 güne kadar uzatılmalıdır.

- Son zamanlarda kullanılmaya başlanan oral antikoagülanlar (Rivaroksaban, Dabigatran) kullanım rahatlığı ve etkinliği açısından ön plana çıkmaktadır. Bu konuda daha çok ve uzun dönemli çalışmaya ve takibe ihtiyaç duyulmaktadır.

\section{KAYNAKLAR}

1. House of Commons Health Committee. The Prevention of Venous Thromboembolism in Hospitalised Patients. Second report of session 2004-05. London: The Stationary Office Limited; 2005.

2. Heit JA, Silverstein MD, Mohr DN, Petterson TM, O'Fallon WM, Melton LJ 3rd. Risk factors for deep vein thrombosis and pulmonary embolism: a population-based case-control study. Arch Intern Med 2000;160(6):809-15.

3. Nagase $Y$, Yasunaga $H$, Horiguchi $H$, Hashimoto $H$, Shoda $N$, Kadono Y, Matsuda S, Nakamura K, Tanaka S. Risk factors for pulmonary embolism and the effects of fondaparinux after total hip and knee arthroplasty: a retrospective observational study with use of a national database in Japan. J Bone Joint Surg Am 2011;93(24):e146. CrossRef

4. Bergqvist D, Hull RD. Effective thromboprophytaxis administered close to the time of major orthopedic surgery: a review. Am J Orthop (Belle Mead NJ) 2006;35(5):226-30.

5. Lee YK, Chung CY, Koo KH, Lee KM, Ji HM, Park MS. Conflict of interest in the assessment of thromboprophylaxis after total joint arthroplasty: a systematic review. J Bone Joint Surg Am 2012;94(1):27-33. CrossRef

6. Caprini JA. Mechanical methods for thrombosis prophylaxis. Clin Appl Thromb Hemost 2010;16(6):668-73. CrossRef

7. Jacobs J, Mont MA, Bozic KJ, Della Valle CJ, Goodman SB, Lewis CG, Yates AC Jr, Boggio LN, Watters WC 3rd, Turkelson CM, Wies JL, Sluka P, Hitchcock K. American Academy of Orthopaedic Surgeons clinical practice guideline on: preventing venous thromboembolic disease in patients undergoing elective hip and knee arthroplasty. J Bone Joint Surg Am 2012;94(8):746-7. CrossRef

8. Colwell CW Jr, Collis DK, Paulson R, McCutchen JW, Bigler GT, Lutz S, Hardwick ME. Comparison of enoxaparin and warfarin for the prevention of venous thromboembolic disease after total hip arthroplasty. Evaluation during hospitalization and three months after discharge. J Bone Joint Surg Am 1999;81(7):932-40.
9. Bauer KA, Eriksson BI, Lassen MR, Turpie AG; Steering Committee of the Pentasaccharide in Major Knee Surgery Study. Fondaparinux compared with enoxaparin for the prevention of venous thromboembolism after elective major knee surgery. N Engl J Med 2001;345(18):1305-10.

10. Westrich GH, Bottner F, Windsor RE, Laskin RS, Haas SB, Sculco TP. VenaFlow plus Lovenox vs VenaFlow plus aspirin for thromboembolic disease prophylaxis in total knee arthroplasty. J Arthroplasty 2006;21(6 Suppl 2):139-43.

11. Brookenthal $K R$, Freedman $K B$, Lotke PA, Fitzgerald $\mathrm{RH}$, Lonner JH. A meta-analysis of thromboembolic prophylaxis in total knee arthroplasty. J Arthroplasty 2001;16(3):293-300.

12. Narani KK. Deep vein thrombosis and pulmonary embolism. Prevention, management, and anaesthetic considerations. Indian J Anaesth 2010;54(1):8-17. CrossRef

13. Burness $C B$, McKeage K. Dabigatran etexilate: a review of its use for the prevention of venous thromboembolism after total hip or knee replacement surgery. Drugs 2012;72(7):963-86. CrossRef

14. Eriksson BI, Borris LC, Friedman RJ, Haas S, Huisman MV, Kakkar AK, Bandel TJ, Beckmann H, Muehlhofer E, Misselwitz F, Geerts W; RECORD1 Study Group. Rivaroxaban versus enoxaparin for thromboprophylaxis after hip arthroplasty. $\mathrm{N}$ Engl J Med 2008;358(26):2765-75. CrossRef

15. Wells PS, Borah BJ, Sengupta N, Supina D, McDonald HP, Kwong LM. Analysis of venous thromboprophylaxis duration and outcomes in orthopedic patients. Am J Manag Care 2010;16(11):857-63.

16. ThakurNA, CzerweinJK, Butera JN, Palumbo MA. Perioperative management of chronic anticoagulation in orthopaedic surgery. J Am Acad Orthop Surg 2010;18(12):729-38.

17. Salvati EA, Pellegrini VD Jr, Sharrock NE, Lotke PA, Murray DW, Potter $\mathrm{H}$, Westrich GH. Recent advances in venous thromboembolic prophylaxis during and after total hip replacement. J Bone Joint Surg Am 2000;82(2):252-70.

18. Pulmonary Embolism Prevention (PEP) Trial Collaborative Group. Prevention of pulmonary embolism and deep vein thrombosis with low dose aspirin: Pulmonary Embolism Prevention (PEP) trial. Lancet 2000;355(9212):1295-302.

19. Haas SB, Barrack RL, Westrich G, Lachiewicz PF. Venous thromboembolic disease after total hip and knee arthroplasty. J Bone Joint Surg Am 2008;90(12):2764-80. 